Araştırma Makalesi / Research Article

\title{
SAĞLIK ÇALIŞANLARINDA HASTA GÜVENLİĞİ KÜLTÜRÜ ALGISININ DEĞERLENDİRILMESİ ÜZERİNE BİR ARAŞTIRMA
}

\author{
Aygen OKSAY* \\ Mehmet KILINÇ** \\ Mehmet SAYHAN***
}

\section{A RESEARCH ON THE EVALUATION OF PATIENT SAFETY CULTURE PERCEPTION IN HEALTH WORKERS}

$\ddot{O} z$

Sağlık sektöründe artan rekabet neticesinde hizmet sunumunda yükselen kalite, hasta güvenliği kavramının önemini arttırmıştır. Verilen hizmet esnasında hastaların güvenliğini tehdit eden herhangi bir unsur insan sağlığ açısından telafi edilemeyen sağlık sorunlarına ya da insan hayatının kaybedilmesine yol açabilmektedir. Bu bakımdan sağlık çalışanlarının hasta güvenliği algıları ve sağlık kurumlarında oluşturulan hasta güvenliği kültürü hizmet kalitesini etkilemekte, insan sağlığı açısından daha da önemli hale gelmektedir. Çalışma sağlık çalışanlarının hasta güvenliği kültürü algısını değerlendirmek, demografik verilerle ilişkisini incelemek amacıyla gerçekleştirilmiştir. Hasta güvenliği kültürüne ilişkin mevcut durumu ortaya koyması açısından uygulamalı ve betimsel bir çalışma niteliğindedir. Çalışma bulgularına göre, sağlık çalışanlarının hasta güvenliği kültürü aritmetik ortalamalarının orta düzeyin üzerinde olduğu saptanmıştır. Hasta güvenliği kültürü ile yaş, görev, görev y1lı ve görev yeri arasında anlamlı ilişki tespit edilmiştir.

Anahtar Kelimeler: Hasta Güvenliği, Sağlık Çalışanları, Sağlıkta Kalite.

\footnotetext{
Abstract

As a result of the increasing participation of public hospitals in the sector, increasing quality in health service delivery increased the importance of the concept of patient safety. Any element that threatens the safety of patients during

* Doç. Dr., Süleyman Demirel Üniversitesi, İİBF, İşletme Bölümü, e-posta: aygenoksay@sdu.edu.tr, https://orcid.org/0000-0002-3186-5010.

** Dr. Öğrencisi, Süleyman Demirel Üniversitesi, SBE, Sağlık Yönetimi Anabilim Dal1, e-posta: mehmetkilinc_@hotmail.com, https://orcid.org/00000001-6835-9325.

*** Dr., Konya Numune Hastanesi, e-posta: drmsayhan@gmail.com, https://orcid.org/0000-0002-4017-9514.

Makale Gönderim Tarihi: 19.12.2018 https://dx.doi.org/10.11616/basbed.v19i47045.499175 Makale Kabul Tarihi $\quad: 14.06 .2019$
} 
the service provided can lead to health problems that cannot be compensated for human health or loss of human life. In this respect, patient safety perceptions of health workers and patient safety culture created in health institutions affect service quality and become more important for human health. The study was conducted to evaluate the perception of health safety of patients and their relationship with demographic data. It is a practical and descriptive study in terms of presenting the current situation of patient safety culture. According to the findings of the study, it was determined that the arithmetic means of the patient safety culture of the health workers were above the medium level.

Keywords: Patient Safety, Health Workers, Quality in Health.

\section{Giriş}

İnsanların sağlı hizmetlerini talep etmelerindeki temel neden kaybettikleri sağlıklarını yeniden kazanmak, mevcut sağlık durumlarını korumak ya da geliştirmek istemeleridir. Yapılan hatalar birçok hizmet sektöründe tolere edilebilirken, sağlık sektöründe çok daha ciddi ve telafisi mümkün olmayan sonuçlara neden olabilmektedir. $\mathrm{Bu}$ durum sağlık hizmetlerinde kalite, hasta güvenliği kültürü gibi kavramların daha da önem kazanmasını sağlamaktadır. Sağlık çalışanları açısından öncelikli hedef, insanlara yardım etmek isterken onlara çeşitli sebeplerle hizmet sunumu esnasında verilebilecek hataları da önlemektir. Fakat sağlık hizmetlerinin karmaşık yapısı birbirinden farklı alanlarda ve çeşitli meslek gruplarından hizmet alınmasını gerekli kılmakta, dolayısıyla tıbbi hata riskini de arttırmaktadır. Hastaların güvenliğini tehdit eden hataların önlenmesi için kurumsal olarak güvenlik kültürünün oluşturulması gerektiği düşünülmektedir (Aydın, 2010: 1; Akalın, 2004: 12-13; Reason, 2000: 768-770).

Öncelikle hastalar için olmak üzere sağlık kurumları, çalışanları ve ülke çapında sağlık harcamaları için de katkıları bulunan hasta güvenliği uygulamalarının bir kurum kültürü olarak sağlık çalışanları tarafından benimsenmesi gerekmektedir. Çünkü hastaların güvenliğini riske eden ya da etme ihtimali olan birçok olayın öncelikle sağlık çalışanları tarafından fark edilmesi yüksek ihtimaldir. Tespit edilen sorunların herhangi bir hastaya zarar vermeden önlenmesi ise çalışanların farkındalığının arttırılması için eğitilmesinden ve hasta güvenliği kültürünün sağlanmasından geçmektedir (Ebik, 2017: 21; Çakır, 2007: 116-117).

Hasta güvenliği, sağlık hizmet sunumu esnasında görülebilecek "basit hatalar" sebebiyle hastalar, hasta yakınları ve sağlık kuruluşu çalışanları için zararla sonuçlanabilecek süreçleri ön görme ve hataları engelleme çabası şeklinde tanımlanabilir (Ovalı, 2010: 34). Kavram temelini "önce zarar verme" anlamına gelen Hipokrat'1n Latince "primum non nocere" 
deyişinden almaktadır (Clarke, 1993: 535). Hasta güvenliği kültürünü daha iyi algılayabilmek için kültür ve kurumsal kültür kavramlarını tanımlamakta fayda bulunmaktadır. Kültür kavramı, bir toplumun üyesi olarak insanoğlunun öğrendiği sanat, bilgi, hukuk, gelenek-görenek, ahlak, inanç ve benzeri alışkanlıklarını içine alan karmaşık bir bütün olarak tanımlanmaktadır (Demirel, 2012: 7-8). Kurumsal kültür ise aynı örgütte çalışanların inanç, tutum, beklenti ve varsayımları ile bireylerarası ilişkileri ve bireylerin davranışlarını belirleyen faaliyetlerin nasıl yürütüldüğünü gösteren normlar denetimidir (Erengül, 1997: 25). Hasta güvenliğinin arttırılması ve hastaların daha güvenli hizmet alabilmesi için dünyanın pek çok ülkesinde yapılan yoğun çalışmalara rağmen elde edilen başarı henüz çok sınırlıdır. Hasta güvenliğini sağlamak amacıyla yapılan çalışmaların başarılı olabilmesi için sektörde bu konuya daha fazla dikkat çekmek, bir ispiyon mekanizması olarak algılanmayan, cezalandırmak ya da suçlamak amacıyla hatayı yapan bireye odaklanmayan, hatalardan öğrenmeyi mümkün kılan bir kültür oluşturmak gerekmektedir. Sağlık çalışanlarının kendilerini dava açılma ya da cezalandırılma riski altında hissetmeden güven içerisinde hataları bildirebilmesi bu kültürün önemli bir parçası olmalıdır (grs.saglik.gov.tr, 02 Nisan 2018).

Maalesef her y1l milyonlarca hasta güvenli olmayan ve kalitesiz sağlık hizmetleri yüzünden ölmekte ya da yaralanmaktadır. Bu ölümlerin ve yaralanmaların çoğu tamamen önlenebilir. Dünyada her yıl tahmini 421 milyon hastane yatışı söz konusudur ve bunların ortalama 10'da 1'i olumsuz olaylara maruz kalmaktadır. Bu, özellikle olumsuz olayların en az yarısının önlenebileceğini bildiğimiz zaman korkutucu bir istatistiktir (www.who.int, 20 Nisan 2018). Türkiye' de sağlık kuruluşlarında çalışan ve hasta güvenliğinin sağlanması için 29 Nisan 2009 tarihinde "Sağlık Kurum ve Kuruluşlarında Hasta ve Çalışan Güvenliğinin Sağlanması ve Korunmasına İlişkin Usul ve Esaslar Hakkında Tebliğ” yayınlanmıştır. $\mathrm{Bu}$ tebliğde ilaç güvenliğinin sağlanması, hastaların kimliklendirilmesi, bilgilerinin tanımlanarak doğrulanması, sağlık çalışanları arasında iletişim güvenliğinin arttırılması, hasta düşmelerinin önlenmesi, enfeksiyon risklerinin azaltılması, sira beklemeden kaynaklanan olumsuzlukların önlenmesi, güvenli cerrahi uygulamalarının geliştirilmesi ve sağlanması, çalışan güvenliği önlemlerinin alınması gibi başlıklara değinilmiş; yapılması gerekenler belirtilmiştir (Resmi Gazete, 29 Nisan 2009).

Tıbbi uygulama hatalarının azaltılması ve hasta güvenliğinin arttırılması için hem sağlık çalışanlarının hem de toplumun bilinç düzeyinin artırılması bir zorunluluktur. Hasta güvenliği bilincini oluşturabilmek için 
sağlık hizmetlerinin ihtiyaç ve değerlere öncelik, tercihlere öncelik, süreklilik, açıklık, şeffaflık ve ekip çalışması gibi bazı özellikleri taşıması gerekmektedir (Hayran, 2009: 20-23). Sağlik kurumlarında kurumsal kültürün en önemli bileşenlerinden birisi hasta güvenliği kültürü olmalıdır. Fakat kurumsal kültür basit bir şekilde değiştirilebilen bir değer değildir. Kurum kültürü, hasta güvenliği kültürü ve kalite kültürü hastane yönetiminde birbirini tamamlayan unsurlardır. Hasta güvenliği odaklı sağlık yönetim sistemlerinin geliştirilmesi yönetim anlayışı, organizasyon yap1sı ve kurum kültürünün hasta güvenliği öncelikli oluşturulması ile ilişkilidir. Ancak kalite kültürü ve kurum kültürünün bir parçası olduğu zaman hasta güvenliği uygulamaları etkili olacaktır (Çakır, 2007: 149).

Sağl1k hizmetlerinde öncelikle hastaya zarar vermeden hizmet sunumunu sağlama gerekliliği, hasta güvenliği kültürünü sağlık kurumlarında oluşturmanın önemini ortaya koymaktadır. Bu önem ve gereklilikten hareketle sağlık çalışanlarının hasta güvenliği kültürü algılarının değerlendirilmesi, demografik özelliklere göre aralarındaki ilişkinin belirlenmesi ile bu kültürün oluşturulmasına ve daha etkin işlemesine olanak sağlayacak önerilerin saptanması önem kazanmaktadır.

\section{Teorik Çerçeve}

\subsection{Hasta Güvenliği ve Hasta Güvenliği Kültürü}

Sunulan sağlık hizmetlerinin kalitesinde ve başarısında hasta güvenliğini sağlayabilmek önemli bir yere sahiptir. $\mathrm{Bu}$ durum ayrıca sağlık kurumlarının ve çalışanlarının hukuki yönden de herhangi bir sorunla karşı karşıya kalmalarını önlemektedir. Hasta güvenliği kavramı daha çok hastaları zarar verici uygulamalardan korumak ve oluşabilecek tehlikelerden uzak tutmak anlamında kullanılırken; hasta güvenliği kültürü ise bir kurumda hastaların güvenliğini sağlamak amacıyla yapılan tüm uygulamaların çalışanlar tarafından benimsenmesini kapsamaktadır.

Hasta güvenliği kavramı, hastanın sağlık bakımıyla ilişkili olarak olası ya da gereksiz zarar görme durumundan uzak tutulması olarak tanımlanmaktadır (Özdemir, 2014: 1). Sağlık hizmetlerinin sunulması esnasında birçok sıkıntının yaşanması olasıdır. Bu sebeple, hastanın herhangi bir zarar görmemesi için sağlık görevlilerinin gerekli önlemleri almaları önemlidir. Hasta güvenliğinin amacı sağlık hizmeti ihtiyacı olan hastalar için güvenlik açısından olumlu bir ortam sağlamak, tehlikelerden ve zarar verecek uygulamalardan onları korumaktır (Uzun, 2009: 1).

Türk Dil Kurumu'na göre kültür kavramı "Tarihsel, toplumsal gelişme süreci içinde yaratılan bütün maddi ve manevi değerler ile bunları 
yaratmada, sonraki nesillere iletmede kullanılan insanın doğal ve toplumsal çevresine egemenliğinin ölçüsünü gösteren araçların bütünü” şeklinde tanımlanmaktadır (www.tdk.gov.tr, 20 Nisan 2018). Bütün organizasyonu birlikte tutan bir kompleks değerler manzumesi olan kurumsal kültür değerler, uygulamalar, paylaşılan ödüller, adetler, öğrenilen işlemler ve inançların tümüyle kolay değiştirilemeyecek şekilde yoğurulmuş bir değerdir. Hasta güvenliğinin organizasyonun ortak değeri ve kurumun önceliği olarak kabul edilmesi kurumun hasta güvenliği kültürü ile ilişkilidir (Akalın, 2004: 12-13). Diğer bir deyişle hasta güvenliği kültürü, "Bireysel ya da grup değerlerin, tutumların, algıların, kabiliyetlerin, kuruma bağlılığı temsil eden davranış şekillerinin, kurumun sağlık ve güvenlik yönetiminin stilinin ve yeterliliğin bir ürünüdür" şeklinde de tanımlanmaktadır (Gülay, 2016: 23).

Kurum kültürünün özelliklerini Özkalp ve Kırel (2001: 162) aşağıdaki gibi sıralamıştır:

- Kurum kültürü, sonradan oluşturulmuş ya da öğrenilmiş bir olgudur.

- Yazılı bir metin olmayan kurum kültürü, örgüt üyelerinin bilinç, bellek ve düşüncelerinde değer ve inançlar bütünü şeklinde bulunur ve çalışanların örgüte olan bağll1ıklarını arttırır.

- Kurum kültürü, kurum çalışanları ve grup üyeleri arasında paylaşılabilir olmalıdır.

- Kurum kültürü, ortaya çıkarılan ya da düzenli şekilde tekrarlanan davranışsal kalıplardır.

- Kültür, kurum çalışanları adına bir kimlik oluşturmaktadır.

- Kültür, bir kurumu diğerlerinden ayıran sinırı çizmektedir.

- Kurum kültürü, çalışanlar için bir kontrol mekanizmasıdır.

Kalite kültürü içerisinde sürekli iyileştirme faaliyetlerine odaklanan sağlık kurumlarında hasta güvenliği kavramı ve güvenlik kültürünün sürekli iyileştirilmesi önem teşkil etmektedir. Güvenlik kültürü, sağlık kurumlarında hastaların güvenliğini sağlamak için önemli unsurları, davranışları, inançları, kuralları ve değerleri kapsamaktadır. Bu yüzden kurumun hasta güvenliği yönetimindeki yetkinliğini, davranış biçimlerini, taahhütlerini, tarzını, tutumlarını ve yeteneklerini belirlemektedir. Güvenlik kültürünü benimsemiş kurumlarda hataları önleyecek tedbirlerin alınmasının önemi, pozitif hasta güvenliği algıları ve güvene dayalı iletişim öne çıkmaktadır. Aynı zamanda örgüt kültürünün de bir unsuru olan hasta güvenliği kültürü, sağlık çalışanlarının algıları, tutumları, değerleri ve inançlarından oluşmaktadır ve sağlık kurumlarında 
hastaların güvenliğini sağlamak için oluşturulmalıdır (Tütüncü vd., 2007: 519).

Kurumlarda hasta güvenliği kültürünün etkin bir şekilde uygulanabilmesi, maddi ve manevi değerlerin doğru belirlenmesinin yanı s1ra hasta güvenliği politikalarının sürdürülebilir olmasına ve birey ya da grupların algılarında kurumun sağlık ve güvenlik stilinin benimsenmesine bağlıdır. Hasta güvenliği kavramının oluşturulmasının temel dayanağı çalışanların bu konuda bilinçlendirilmesi ve güvenlik parametrelerinin sağlık kurumu içerisinde uygulatılabilmesidir. Bu kavramların geliştirilmesindeki en önemli unsuru hastane üst yönetimleri tarafindan desteklenen kalite ve hasta güvenliği çalışmaları oluşturmaktadır (Gülay, 2016: 5-24). Hasta güvenliğinin kurum kültürünün bir unsuru olarak yerleşmesini sağlayabilmenin en önemli noktaları Altındiş (2014: 70-71) tarafından aşağıdaki gibi sıralanmıştır:

- Hasta güvenliğinin tüm çalışanlar tarafından sahiplenmesinin ilan edilmesi,

- Açık iletişimin liderlerden çalışanlar ve hastalara kadar herkesin arasında sağlanmasının teşvik edilmesi,

- Hastaların güvenliğini riske eden işlemleri tespit etme ve azaltma sorumluluğunun çalışanlara devredilmesi,

- Hastaların güvenliğini sağlamak için kaynak oluşturulması,

- Hasta güvenliği eğitimlerinin sürekli hale getirilmesidir.

Güvenlik kültürünün oluşturulabilmesi için sağlık çalışanlarının hastaların sağlığını tehdit eden olası ya da mevcut hataları cezalandırılmaktan korkmadan raporlayabilmeleri ve kurum içerisinde açık ve tutarlı iletişimin sağlanması gereklidir (Milligan ve Dennis, 2005: 48-52).

\subsection{Dünyada ve Türkiye'de Hasta Güvenliği}

Dünyada ve Türkiye'de hastaların daha güvenilir şekilde sağlık hizmeti almalarını sağlamak için birçok çalışma yürütülmektedir. Uygulamaya koyulmaya çalışılan hasta güvenliği politikalarında en önemli hususlardan birisi de yapılan hatalardan ders çıkarmak ve gerçekleşen ya da gerçekleşmeden fark edilen olayların etkin şekilde bildiriminin yapılmasını sağlamaktır. Türkiye'de ve çeşitli ülkelerde bildirimlerin etkin şekilde yapılmasını sağlamak için çalışmalar devam etmektedir.

Institute of Medicine tarafindan 1999 yılında “To Err Is Human” raporu yayınlanana ve bu raporun tüm dünyada ses getirmesine kadar birçok tıbbi hata belki de "normal” kabul edilmiştir. Bu raporda A.B.D'de yılda 
44.000 ile 98.000 arasında hastanın tıbbi hata kaynaklı öldügü belirtilmektedir. Bu sayı trafik kazası veya meme kanseri sebebiyle ölümlerden daha yüksektir. Önlenebilecek olan tıbbi hataların yarattığı ölüm ya da sakatlıkların neticesinde verilen ek sağlık hizmeti gibi nedenler A.B.D.'ye bir y1lda 17 milyar dolarla 29 milyar dolar arasında gelir kaybına mal olmaktaydı. Yapılan tahminler gerçekleşen tıbbi hataların toplamda maliyetinin 37,6-50 milyar Dolar arasında olduğu üzerineydi (Kohn vd., 1999: 26-27). Schoen vd. (2005: 521) tarafindan gelişmiş sağlık sistemine sahip altı ülkede yapılan çalışma bulgularına göre hastaların tıbbi hata yapıldığını düşünme düzeyleri "İngiltere'de $\% 22$, Almanya'da \%23, Yeni Zelanda'da \%25, Avustralya'da \%27, Kanada'da \%30 ve Amerika Birleşik Devletleri'nde \%34” olarak bulunmuştur. $\mathrm{Bu}$ veriler hastalar, hasta yakınları, sağlık çalışanları, yöneticiler, basın, politikacılar ve dolayısıyla kamunun gözünden kaçmayacak kadar önemli verilerdir. Tartışmaların neticesinde İngiltere'de yatışı verilen hastaların \%10'undan daha fazla bir kısmında, yaklaşık olarak yılda 850.000 istenmeyen olay yaşandığı görülmüştür. Avustralya'da ise istenmeyen olay sıklığının \%16,6 olduğu belirlenmiştir. Bunun gibi gelişmeler Amerika, Avustralya ve İngiltere ile batı dünyası liderliğinde 2000 y1lından sonra Sağlıkta Hasta Güvenliği Dönemi’ni başlatmıştır (Çakmakçı, 2014: 8).

Bugün tüm dünyada sağlık kurumlarında hasta güvenliği kültürüne duyulan ihtiyaç kabul edilmekte fakat uygulamasında birçok sorunla karş1 karşıya kalınmaktadır. Sağlık bakım kuruluşları çözüm bulabilmek için hastaya zarar verme ihtimali olan riskleri kontrol etmek, önlemek amacıyla yapılacakları belirlemek, kaliteli bir şekilde bakım ve hasta güvenliği programlarını hazırlamak ve stratejik bir şekilde uygulamaya çalışmak zorundadırlar (Johnstone ve Kanitsaki, 2006: 383). Dünya Sağlık Örgütü (DSÖ) tarafından Cenevre'de gerçekleştirilen 2007 yılındaki uluslararası konferans Avrupa Komisyonu tarafından desteklenmiş ve dünyada her yıl yaklaşık olarak 10 milyon insanın önlenebilir tıbbi hatalardan dolayı öldügünü ya da sakatlandığını belirterek hasta güvenliği hakkında daha çok çalışma yapılması gerektiğini bildirmiştir (www.who.int, 23 Nisan 2018).

Tüm dünyada karşılaşılan tıbbi hatalar hasta güvenliğini riske etmekte ve en önemli sağlık sorunlarından birisi olarak görülmektedir. Tıbbi hataların kaydedilmesi üzerine oluşturulan sistemler gelişmiş olan ülkelerde hasta güvenliğini tehdit altına alan durumların belirlenmesine ve önlenmesine yardımcı olmaktadır. Gelişmemiş veya gelişmekte olan ülkelerde görülen tıbbi hatalar ya da hastaların güvenliğini tehdit eden olumsuz olaylar kalitesiz tıbbi malzeme/ilaç kullanılması, enfeksiyon 
kontrolünün yetersizliği, güvensiz sağlık hizmeti arzı, motivasyon veya teknik bilgi yetersizliği sebebiyle personelin düşük performansı, atık yönetiminin tam anlamıyla sağlanamaması, artan maliyetler ve finansman sorunları şeklinde sıralanabilir (Özdemir, 2014: 9-10).

Hasta güvenliği sorunlarının belirlenmesinde temel araç, sağlık hizmeti sunumu esnasında hastaların maruz kaldıkları hataların sağlık çalışanları tarafından raporlanmasıdır. Gerçekleşen ya da gerçekleşmesine ramak kalan olayların raporlanması, sık gerçekleşen hataların tespit edilmesini, analizinin yapılmasını ve değerlendirilmesini, hata ciddiyetinin ve sıklığının azaltılmasını sağlar. Ayrıca olayların raporlanması kurum içerisinde tehlikeli alanların saptanmasına ve hatanın kaynağına ilişkin bilgiler üreterek yapılacak iyileştirmelerin yolunun açar (Eroğlu, 2011: 73).

Hata bildirimlerinde dünyada görülen genel yaklaşım hatayı yapan bireye değil hataya odaklanmaktır. Fakat birçok ülke hata bildirim sistemlerinde yeterli kimliksizleştirme (anonimizasyon) şartlarını yerine getiremediği için ulusal düzeyde bir güvenlik raporlama sistemi oluşturamamaktadır. Yeteri miktarda ve doğru bildirim alabilmek için toplumsal, organizasyonel ve kişisel çeşitli sorunların giderilmesi gerekmektedir. Bu sebeple güvenlik raporlama sistemlerinde anonimizasyon, yani kimliksizleştirme ilk şart olarak karşımıza çıkmaktadır. Türkiye'de sağlık çalışanlarının ve tesislerinin tıbbi süreçlerde karşı karşıya kaldıkları hataları bildirebilecekleri, ülke genelinde sıklıkla gerçekleşen hatalar ve iyileştirilmesine dönük önlemlerle ilgili bilgi alabilecekleri Güvenlik Raporlama Sistemi (GRS) platformu oluşturulmuştur. GRS anonimizasyonu sağlamak adına herhangi bir manuel veri girişine imkân tanımamakta; bildirim esnasında lokasyon bilgisi, IP adresi, kişi adı vb. hiçbir kişisel bilgiyi veri tabanına kaydetmemektedir. Geliştirilen GRS sistemi ile amaçlanan unsurlar aşağıdaki gibidir (grs.saglik.gov.tr, 02 Nisan 2018);

- Tıbbi süreçler sırasındaki hataları ulusal çapta toplamak,

- Sistemsel olarak iyileştirilmenin sağlanması ve kalite standartlarının geliştirilmesi için toplanan bildirimlerin kullanılmas1,

- Sağlık çalışanlarının farkındalığını tıbbi hatalar ve bu hataların bildirimi konusunda artırmak,

- Sağlık kurumlarına toplanan raporlar aracillğıyla iyileştirme firsatları bakımından yol göstermek,

- İç güvenlik raporlama sistemlerinin oluşturulması hakkında sağlık kurumlarına bilgi merkezi aracılığıyla rehberlik etmektir. 
Yapılan çalışmalar olayın çalışan kişilerce küçümsendiği zamanlarda yapılan bildirimlerin azaldığını ve iyileştirme şansının yok olduğunu belirtmektedir. Fakat hasta güvenliğinin ana unsuru bildirimden geçmektedir. Ne yaşandığını saptamak ve bunların analizini yaparak iyileştirmek hasta güvenliğini iyileştirmenin temelidir. Olay bildirimlerinin ana özelliklerini aşağıdaki gibi sıralamak mümkündür (Çakmakçı ve Akalın, 2010: 83):

- Olay araştırılırken kesin hüküm verme veya suçlama niyetiyle değil olayı öğrenme amaçlı sorgulama yapılır.

- Hasta güvenliği bildirimlerinin sürekliliğini sağlamak amaciyla bildirim yapan kişi tespit edilmeye çalışılmaz, cezalandırmaz.

- Olay bildirimi hızlı ve zaman kaybedilmeden yapılabilmelidir. Zaman olay yerini inceleme açısından önemlidir.

- Olaylar sinıflandırılarak tekrarlama riski ve ciddiyetine göre ayrı ayrı değerlendirilmelidir.

- Tüm çalışanların olay bildirimlerine katkıda bulunması sağlanmalıdır. Özellikle çoğu bildirim hemşirelerce yapılmakta olup hekim grubunun da olay bildirimi yapmasına yönlendirilmesi gerekir.

\subsection{Hasta Güvenliğinin Önemi ve Amaçları}

Hasta güvenliğinin sağlanması farklı meslek gruplarına eğitim verilmesi, çalışanlara güven vererek bildirimlere hassasiyet gösterilmesinin sağlanması, güvenlik raporlama sistemlerinin sağlık kurumları içerisinde oluşturulmas1 ve güvenlik kültürünün benimsenmesi gibi birçok çalışmayı gerektirse de sonuçları belki de bir kişi bile olsa insan yaşamına etki edeceği için oldukça önemlidir. Dolayısıyla hasta güvenliğinin öncelikli amacı sağlik kurumuna giren her kişinin önceki durumundan daha sağlıklı çıkması ya da herhangi bir sebeple zarar görmemesidir.

Hasta güvenliğinin sağlanmasında, sağlık hizmetlerinin sunulduğu aşamaların her birinde önlemlerin alınması gerekmektedir. Sağlık hizmetinin sunumunda her an bir tehlike yaşanması muhtemeldir. $\mathrm{Bu}$ sebeple, bir süreç olarak değerlendirildiğinde, sağlık hizmetlerinin sunumunda baştan sona kadar bütün tedbirlerin alınmış olması gerekmektedir. Unutmamak gerekir ki sağlık hizmetlerinde amaç bireyin sağlık sorununun ortadan kaldırılmasıdır. $\mathrm{Bu}$ sebeple, hasta güvenliğindeki amaç bireyin yeni sağlık sorunlarını bakım esnasında yaşamamasıdır. Dolayısıyla hasta bakımının yapıldığı ortamlardaki fiziki ve beşeri tüm olasıllklar dikkate alınmalı ve gerekli tedbirler uygulanmalıdır (Yetginlioğlu, 2009: 36). 
Hasta güvenliğinin bir başka amacı ise hastaları, hasta yakınlarını ve çalışanları psikolojik ve fiziki olarak pozitif yönde etkileyecek ortam oluşturarak güvenliği sağlamaktır. Beklenen hedef, hizmet sunumunda hataların oluşmasının önüne geçmek, olası zararlardan bireyleri korumak ve hata olma olasılığını yok etmektedir (Güven, 2007: 411). Serbest (2011: 14) tarafından yazında genel kabul gören altı hedef aşağıdaki gibi siralanmaktadir:

- Düşme kaynaklı zarar görme risklerinin azaltılması,

- Hastaların doğru şekilde tanımlanmasi/kimliklendirilmesi,

- Yüksek riskli ilaç güvenliğini sağlama,

- Etkili iletişimin iyileştirilmesi,

- Sağlık bakımı ile ilişkili enfeksiyonların düşürülmesi,

- Doğru hasta, doğru prosedür ve doğru taraf cerrahisinin sağlanması.

Sağlık kurumu içerisindeki güvenlik kültürü, sadece hastalar için değil, hastane çalışanları için de olumlu sonuçlar doğurmaktadır. Güçlü bir güvenlik kültürü, hastaların ve sağlık çalışanlarının fiziksel ve psikolojik olarak olumsuz durumlarla karşılaşma oranlarını en aza indirecektir. Hasta güvenlik kültürünün oluşmasındaki amaç, sağlık hizmetlerinin sunulması esnasında önceki sayfalarda belirtilen hataların oluşmasını engelleyecek sistemlerin kurulmasıdır. Hastaların güvenliğini sağlayabilmek amacıyla, güvenlikle ilişkili konuları öğrenmek ve paylaşmak, kurumlarda güvenlik kültürü oluşturmak, risk yönetimi konusunda çeşitli aktiviteleri entegre etmek, hastalarla ve toplumla iletişim kurmak, kayıt gerçekleştirmek, zararları önleme konusunda çözümler sağlamak ve ekip çalışanlarına rehberlik yaparak onları desteklemek gerekmektedir (NPSA, 2004).

Geleneksel olarak süregelen yaklaşımda yapılan hatalarda suçlu aranmakta ve güvenlik ortamının oluşturulması için bireylere odaklanılarak tepki verilmektedir. Oysa sağlık sektöründe güvenlik kültürünün geliştirilmesi için en önemli etken hasta güvenliğinin önceliğinin kabullenildiği bir çalışma ortamının oluşturulmasıdır. Kurumun hasta güvenliği değerlerini yönetim, iletişim ve geribildirim etkilemektedir. Yönetim, üretkenlik ve güvenlik dengesini, ekip çalışmasını ve güvenliği oluşturma sürecini sağlamalıdır. Sağlık personelleri arasında gerçekleşen açık iletişimin desteklendiği çalışma ortamı güvenlik kültürünün oluşması için çok önemlidir. Çalışanlardan doğru anlarda bildirim alan sağlık kurumlarının olası hataları önlemede daha etkili oldukları belirlenmiştir (Reason, 1995: 80-89). 
21. yüzyıl sağlık alanında da birçok alanda olduğu gibi hizmet algısını değiştirmiş, hastaların sağlık hizmetlerinin sunumunda yalnızca tıbbi hizmetlerde değil, aynı zamanda hasta bakımında da daha iyi hizmet talep etmelerini sağlamıştır. Günümüzde sağlı kurumları nitelikli hizmet verebilmek için bazı ana unsurları yerine getirmelidir. Sağlık sisteminde amaçlanan iyileştirme konuları aşağıdaki şekildedir (Özdemir, 2014: 34):

- Zamanında sağlık hizmeti: Minimum bekleme süreleriyle zararın önlenmesi,

- Etkili sağlık hizmeti: Bilimsel bilgi ve kanıta dayalı tıpla hizmet sunumu, sağlık hizmetinin az ya da gereksiz kullanımın önüne geçilmesi,

- Eşit dağılım: Sağlık hizmet kalitesinin renk, cinsiyet, 1rk, sosyoekonomik farklılık ve coğrafyaya bakılmaksızın eşit olması,

- Hasta güvenliğini sağlama: Hastalara zarar vermekten sakınma,

- Hasta odaklı sağlık hizmeti: Hasta değerlerinin, ihtiyaçlarının ve tercihlerinin göz önünde bulundurularak hastaların klinik karar verme mekanizmalarına ortak edilmesi,

- Verimli sunulan sağlik hizmeti: Maliyet etkin ve israfin engellendiği bir hizmet sunumu,

Hasta güvenliğinin sağlanması, sağlık hizmetlerinin sunumunun kaliteli bir şekilde sunulabilmesi için oldukça önemlidir. Hastanın sahip olduğu sorunun giderilmesinden önce, hastanın herhangi başka bir sağlık sorunu yaşamamasının önüne geçilmesi gerekmektedir. Ĕger sağlık hizmetlerinin sunumu esnasında, hasta yeni sağlık sorunlarını ihmaller sebebiyle yaşıyorsa, sunulan sağlık hizmetlerinde kalitenin eksik olduğu görüşü savunulabilir. Sağlıkta kaliteli bakım sağlamanın en önemli basamaklarından birisi hasta güvenliğidir (Tunçel, 2013: 4).

\section{Araştırmanın Amacı, Yöntemi, Verilerin Analizi ve Bulguları}

Sağlık çalışanlarının hasta güvenliği kültür düzeylerinin değerlendirilmesinin, sektörel açıdan hizmet kalitesini yükselteceği, hasta güvenliğini tehdit edebilecek olayları azaltacağı ve sonuç olarak hata nedeniyle oluşacak kalıcı sağlık sorunlarının ya da ölümlerin kısmen de olsa engellenebileceği düşünülmektedir. $\mathrm{Bu}$ bakımdan araştırmanın amac1, sağlık çalışanlarının hasta güvenliği kültür düzeylerinin belirlenmesi ve hasta güvenliği kültürü ile demografik değişkenler arasındaki ilişkinin incelenmesidir. 
Çalışma sağlık kurumlarında hasta güvenliği kültürü ile ilgili var olan durumu belirlemesi açısından betimsel ve uygulamalı bir çalışma niteliğgindedir. Çalışma evreni Konya Numune Hastanesi'nin sağlık çalışanlarından oluşmaktadır ve örneklem büyüklüğünün saptanmasında toplam sağlık çalışanı sayısı göz önüne alınmıştır. Konya Numune Hastanesi'nde 1012 sağlık çalışanı bulunmaktadır.

1012 kişinin bulunduğu evrenden basit tesadüfi örnekleme yöntemiyle ulaşılması gereken örneklem sayısı aşağıda yer alan formül (İslamoğlu, 2009: 171) yardımıyla hesaplanarak $\% 95$ güven düzeyinde 278 olarak tespit edilmiştir.

$$
n=\frac{\mathrm{Z}^{2} \mathrm{PQ}}{\mathrm{E}^{2}+\frac{\mathrm{Z}^{2} \mathrm{PQ}}{\mathrm{N}}}=\frac{1,96^{2} * 0,5 * 0,5}{0,05^{2}+\frac{1,96^{2} * 0,5^{*} 0,5}{1012}}=278
$$

Çalışma verileri anket yöntemi ile toplanmıştır. Belirlenen örneklem miktarını sağlamak amacıyla toplam 320 anket araştırmacılar tarafindan 05-28 Kasım 2018 tarihleri arasında sağlık çalışanlarına basit tesadüfi örneklem yöntemi ile dağıtılmış ve geri dönüşü yapılan ancak 287 anket olmuştur. Geri dönenler içinde 6 anket yanlış veya eksik doldurulduğundan 281 anket çalışmada kullanılabilmiştir. Anketlerin geri dönüş oranı \%89'dur. Anket iki bölümden oluşmaktadır. İlk bölümde katılımcıların demografik verilerini saptamaya dönük sorular bulunmaktadır. İkinci bölümde ise çalışanların hasta güvenliği kültürü konusunda algılarını belirlemeye yönelik ölçek yer almaktadır.

Hasta Güvenliği Kültürü Hastane Anketi A.B.D'de 2004 yılında, Sağlık Hizmetlerinde Araştırma ve Kalite Ajansı tarafindan hastanelerde hasta güvenliği kültürünü saptamak amaciyla geliştirilmiş̧tir (Sorra ve Nieva, 2004). Anket 42 madde ve 12 alt alandan oluşmaktadır. Anketin Türkçe'ye uyarlanması ve geçerlik, güvenirlik çalışması Filiz (2009: 52) tarafindan yapılmış ve Cronbach's Alpha katsayısı 0,864 bulunmuştur. Bu çalı̧̧mada geçerlik analizi için ölçekteki her bir boyut birbirleriyle ilişkilendirilmiştir ve boyutlar arasında orta düzeyde korelasyon $(0,18$ 0,63 arasında) saptanmıştır. Boyutlar arasında yüksek korelasyon $(0,85$ ve üzeri) çıkmaması aynı yapıyı ölçen güvenlik kültürü boyutlarının bulunmadığını göstermektedir. Yapılan faktör analizi sonucunda ise 42 maddenin 12 faktör altında toplandığı belirlenmiş ve ölçeğin orjinaliyle uyum sağladığı görülmüştür. Ölçeğin Cronbach's Alpha katsayısı 0,906 olarak hesaplanmıştır. Ölçek ifadelerine beş dereceli Likert tipi derecelendirme uygulanmıştır. Ölçekte en çok 210 en az 42 puan alınabilmektedir. Puanın yüksek olması hasta güvenliği kültürü algısının 
yüksek olduğu anlamına gelmektedir. Toplam 18 madde olumsuz maddelerdir ve ters puanlandırılarak analiz edilmiş̧ir.

Verilerin normal dağılıma uygunluğu Çarpıklık (Skewness) katsayısı ve Kolmogrov-Smirnov testiyle incelenmiştir. Büyüköztürk (2011: 40)'e göre "Sürekli bir değişkenden elde edilen puanların normal dağılım özelliğinde kullanılan çarpıklık katsayısının (Skewness) \pm 1 sınırları içinde kalması puanların normal dağılımdan önemli bir sapma göstermediği şeklinde yorumlanabilir". Yapılan normallik kontrolünde ölçek puanlarının normal dağılımda olduğu belirlenmiştir. Ölçek puanlarının eğitim durumu, yaş, görev, görev yeri ve görev y1lı değişkenlerine göre karşılaştırılmasında tek yönlü varyans analizi (One Way ANOVA) testi; cinsiyet ve medeni durum değişkenlerine göre karşılaştırmasında ise bağımsız iki örneklem $t$ testi (independent samples $\mathrm{t}$ test) uygulanmıştır. ANOVA testine göre anlamlı farklılık görülen gruplarda farkın hangi gruplar arasında olduğunu tespit etmek için LSD post hoc testinden faydalanılmıştır. Anlamlılık düzeyi uygulanan analizlerde $0,05(\mathrm{p}<0,05)$ olarak belirlenmiştir.

Örneklemini sağlık çalışanlarının oluşturduğu bu araştırma kapsamında katılımcıların demografik (cinsiyet, yaş, medeni durum ve eğitim durumu) ve diğer bireysel özelliklerine (hastanede çalışma y1l, kurumdaki görevi, Güvenlik Raporlama Sistemine bildirim sayıs1 ve hasta güvenliği konusunda birimlerini değerlendirmeleri) ilişkin bilgiler Tablo 1'de detaylı olarak verilmiştir. Örneklem dağılımı evren ile karşılaştırılmış ve benzerlik gösterdiği tespit edilmiştir.

Tablo 1: Demografik Bulgular

\begin{tabular}{|l|l|c|c|}
\hline \multicolumn{2}{|l|}{} & \multicolumn{1}{|c|}{ Sayi (n) } & $\begin{array}{c}\text { Yüzde } \\
\text { (\%) }\end{array}$ \\
\hline \multirow{5}{*}{ Cinsiyet } & Kadın & 182 & 64,8 \\
\hline & Erkek & 99 & 35,2 \\
\hline \multirow{5}{*}{ Yaş } & Toplam & 281 & 100,0 \\
\hline \multirow{3}{*}{ Medeni Durum } & $18-25$ & 32 & 11,4 \\
\hline & $26-35$ & 62 & 22,0 \\
\hline & $36-45$ & 121 & 43,1 \\
\hline \multirow{5}{*}{ Eğitim Düzeyi } & 46 ve üzeri & 66 & 23,5 \\
\hline & Toplam & 281 & 100,0 \\
\hline & Evli & 205 & 73,0 \\
\hline & Bekar & 76 & 27,0 \\
\hline & Toplam & 281 & 100,0 \\
\hline & Lise & 33 & 11,7 \\
\hline & Önlisans & 68 & 24,2 \\
\hline & Lisans & 124 & 44,1 \\
\hline & Lisansüstü & 56 & 19,9 \\
\hline
\end{tabular}




\begin{tabular}{|c|c|c|c|}
\hline & Toplam & 281 & 100,0 \\
\hline \multirow{6}{*}{ Kurumda Çalışma Süresi } & 1 y1ldan az & 32 & 11,4 \\
\hline & $1-5 \mathrm{y} 1 \mathrm{l}$ & 71 & 25,3 \\
\hline & 6-10 y1l & 52 & 18,5 \\
\hline & $11-15$ y1l & 50 & 17,8 \\
\hline & 16 y1l ve üzeri & 76 & 27,0 \\
\hline & Toplam & 281 & 100,0 \\
\hline \multirow{5}{*}{ Kurumdaki Görev } & Doktor & 33 & 11,7 \\
\hline & Hemşire & 146 & 52,0 \\
\hline & Teknisyen/Tekniker* & 64 & 22,8 \\
\hline & Tibbi Sekreter & 38 & 13,5 \\
\hline & Toplam & 281 & 100,0 \\
\hline \multirow{6}{*}{ Çalışılan Birim } & Klinik & 117 & 41,6 \\
\hline & Yoğun Bakım & 31 & 11,0 \\
\hline & Ameliyathane & 35 & 12,5 \\
\hline & Acil & 27 & 9,6 \\
\hline & Diğer & 71 & 25,3 \\
\hline & Toplam & 281 & 100,0 \\
\hline \multirow{6}{*}{$\begin{array}{l}\text { Hasta Güvenliği Konusunda Biriminizi } \\
\text { Değerlendiriniz? }\end{array}$} & Mükemmel & 59 & 21,0 \\
\hline & Çok İyi & 111 & 39,5 \\
\hline & Kabul Edilebilir & 82 & 29,2 \\
\hline & Zayıf & 24 & 8,5 \\
\hline & Başarısız & 5 & 1,8 \\
\hline & Toplam & 281 & 100,0 \\
\hline \multirow{5}{*}{$\begin{array}{l}\text { Güvenlik Raporlama Sistemine } \quad \text { (GRS) } \\
\text { Yapılan Bildirim Sayısı }\end{array}$} & Hiç & 224 & 79,7 \\
\hline & $1-2$ & 32 & 11,4 \\
\hline & $3-5$ & 14 & 5,0 \\
\hline & 6 ve üzeri & 11 & 3,9 \\
\hline & Toplam & 281 & 100,0 \\
\hline
\end{tabular}

* Röntgen, Anestezi, Acil Tıp ve Laboratuvar Teknisyen/Teknikerleri

Tablo 1'den de görüldüğü üzere, katılımc1ların \%64,8'i (n=182) kadın, \%43,1'i (n=121) 36-45 yaş aralığında, \%73'ü $(n=205)$ evli ve \%44,1'i $(\mathrm{n}=124)$ lisans mezunudur. Ayrıca katılımciların \%27'sinin $(\mathrm{n}=76) 16$ yıl ve daha fazla süredir kurumda çalıştığı, \%52'sinin $(n=146)$ hemşire olduğu ve \%41,6’sının (n=117) kliniklerde çalıştığı tespit edilmiştir. Katılımcıların \%60,5'inin çalıştıkları birimi hasta güvenliği açısından çok iyi veya mükemmel olarak değerlendirdiği ve \%79,7'sinin $(n=224)$ Güvenlik Raporlama Sistemine (GRS) hiç hata bildiriminde bulunmadiğ belirlenmiştir.

Tablo 2'de ölçeğin alt boyutlarının ifade sayıları, katılımcıların hasta güvenliği kültürü puanlarının aritmetik ortalaması, çarpıklık katsayısı ve standart sapma değerleri belirtilmiştir. 
Tablo 2: Hasta Güvenliği Ölçeği Betimsel İstatistikleri

\begin{tabular}{|c|c|c|c|c|c|c|}
\hline Ölçek ve Alt Boyutları & 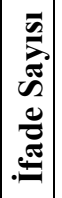 & $\dot{\Xi}$ & $\frac{\dot{\vec{D}}}{\sum^{\frac{\pi}{\Sigma}}}$ & $\mathrm{X}$ & के & 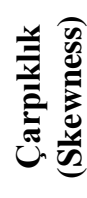 \\
\hline 1 Alg1lann & 4 & 2,00 & 5,00 & 4,03 & 0,16 & $-0,48$ \\
\hline Hataların Raporlanma Sıklığı & 3 & 1,00 & 5,00 & 3,47 & 0,18 & $-0,28$ \\
\hline Hastane Üniteleri Arasında Ekip Çalışm & 4 & 1,50 & 5,00 & 3,59 & 0,17 & $-0,57$ \\
\hline Hastane Müdahaleleri ve Değişim & 4 & 2,00 & 5,00 & 3,90 & 0,15 & $-0,34$ \\
\hline $\begin{array}{l}\text { Yönetici Beklentileri ve Güvenlik Geliştirme } \\
\text { Faaliyetleri }\end{array}$ & 4 & 1,00 & 5,00 & 3,54 & 0,19 & $-0,48$ \\
\hline Organizasyonel Öğrenme ve Sürekli Geliştirme & 3 & 1,33 & 5,00 & 3,80 & 0,12 & $-0,85$ \\
\hline Üniteler İçinde Ekip Çalışması & 4 & 1,25 & 5,00 & 4,19 & 0,15 & $-1,22$ \\
\hline İletişimin Açık Tutulması & 3 & 1,00 & 5,00 & 3,51 & 0,14 & $-0,38$ \\
\hline Hatalar Hakkında Geri Bildirim ve İletişim & 3 & 1,33 & 5,00 & 3,87 & 0,13 & $-0,84$ \\
\hline Hataya Karşı Cezalandırıcı Olmayan Yanıt & 3 & 1,00 & 5,00 & 3,10 & 0,15 & $-0,12$ \\
\hline Personel Sağlama & 4 & 1,50 & 4,75 & 2,82 & 0,15 & 0,31 \\
\hline \begin{tabular}{|l}
$\begin{array}{l}\text { Hasta Güvenliği İçin Hastane Yönetiminin } \\
\text { Desteği }\end{array}$ \\
\end{tabular} & 3 & 1,00 & 5,00 & 3,65 & 0,14 & $-0,61$ \\
\hline HASTA GÜVENLİĞİ KÜLTÜRÜ TOPLAM & 42 & 2,19 & 4,64 & 3,63 & 1,14 & $-0,13$ \\
\hline
\end{tabular}

Katılımcıların hasta güvenliği kültürü toplam puan aritmetik ortalamaları 3,63 olarak orta düzeyin üzerinde bulunmuştur. Ölçek alt boyut puanlarında çalışanların en düşük algılarının personel sağlama $(2,82)$, hataya karşı cezalandırıcı olmayan yanıt $(3,10)$ ve hataların raporlanma sıklığında $(3,47)$, en yüksek algılarının ise üniteler içinde ekip çalışmasında $(4,19)$ olduğu belirlenmiştir.

Tablo 3: Hasta Güvenliği Kültürü Puanlarının Cinsiyet ve Medeni Duruma Göre Karşılaştırılması

\begin{tabular}{|c|c|c|c|c|c|c|}
\hline Boyut & $\begin{array}{l}\text { Cinsiyet / Medeni } \\
\text { Durum }\end{array}$ & $\mathbf{n}$ & $\overline{\mathbf{X}}$ & SS & $\mathbf{t}$ & p \\
\hline \multirow{4}{*}{$\begin{array}{l}\text { Hasta Güvenliği Kültürü } \\
\text { Toplam }\end{array}$} & Kadın & 182 & 3,61 & 0,45 & \multirow[b]{2}{*}{$-0,83$} & \multirow[b]{2}{*}{0,41} \\
\hline & Erkek & 99 & 3,66 & 0,47 & & \\
\hline & Evli & 205 & 3,62 & 0,43 & \multirow{2}{*}{$-0,29$} & \multirow{2}{*}{0,77} \\
\hline & Bekar & 76 & 3,64 & 0,53 & & \\
\hline
\end{tabular}

Cinsiyet ve medeni durum ile hasta güvenliği kültürü arasındaki ilişkiyi tespit etmek amaciyla t testi yapılmıştır. Tablo 3 'de görüldüğü üzere hasta güvenliği kültürü ile cinsiyet $(\mathrm{t}=-0,83 ; \mathrm{p}>0,05)$ ve medeni durum $(\mathrm{t}=-0,29 ; \mathrm{p}>0,05)$ arasında anlamlı farklılık bulunmadığı tespit edilmiştir. 
Tablo 4: Hasta Güvenliği Kültürü Puanlarının Yaş Değişkenine Göre Karşılaştırılması

\begin{tabular}{|c|c|c|c|c|c|c|c|}
\hline Boyut & Yaş & $\mathbf{n}$ & $\overline{\mathbf{X}}$ & SS & $\mathbf{F}$ & $\mathbf{p}$ & $\begin{array}{c}\text { Anlamlı } \\
\text { Fark }\end{array}$ \\
\hline \multirow{4}{*}{$\begin{array}{l}\text { Hasta Güvenliği* } \\
\text { Kültürü Toplam }\end{array}$} & A- $18-25$ & 32 & 3,84 & 0,53 & \multirow{4}{*}{2,882} & \multirow{4}{*}{0,036} & \multirow{4}{*}{$\mathbf{A}>\mathbf{B}, \mathbf{C}, \mathbf{D}$} \\
\hline & B- $26-35$ & 62 & 3,64 & 0,48 & & & \\
\hline & C- $36-45$ & 121 & 3,60 & 0,43 & & & \\
\hline & D- 46 ve üzeri & 66 & 3,57 & 0,42 & & & \\
\hline
\end{tabular}

Çalışanların hasta güvenliği kültürü puanlarının yaşa göre anlamlı farklılık gösterdiği belirlenmiştir $(\mathrm{F}=2,762 ; \mathrm{p}<0,05)$. Farkın kaynağına ilişkin yapılan LSD post hoc testi sonuçlarına göre 18-25 yaş aralığında olan çalışanların hasta güvenliği kültürü puanları, 26-35, 36-45 ile 46 ve üzeri yaş grubundaki çalışanların puanlarından anlamlı düzeyde daha yüksektir. Bu analiz sonucuna göre diğer yaş gruplarından daha genç olan 18-25 yaş arasındaki çalışanların hasta güvenliği konusunda daha duyarlı oldukları söylenebilir.

Tablo 5: Hasta Güvenliği Kültürü Puanlarının Eğitim Değişkenine Göre Karşılaştırılması

\begin{tabular}{|l|c|c|c|c|c|c|c|}
\hline Boyut & Ĕ̆itim Düzeyi & $\mathbf{n}$ & $\overline{\mathbf{X}}$ & $\mathbf{S S}$ & $\mathbf{F}$ & $\mathbf{p}$ & $\begin{array}{c}\text { Anlamlı } \\
\text { Fark }\end{array}$ \\
\hline \multirow{3}{*}{$\begin{array}{l}\text { Hasta Güvenliği } \\
\text { Kültürü Toplam }\end{array}$} & A- Lise & 33 & 3,62 & 0,34 & & & \\
\cline { 2 - 6 } & B- Önlisans & 68 & 3,56 & 0,47 & \multirow{3}{*}{2,109} & 0,099 & - \\
\cline { 2 - 6 } & C- Lisans & 124 & 3,60 & 0,44 & & & \\
\cline { 2 - 5 } & D- Lisansüstü & 56 & 3,76 & 0,50 & & & \\
\hline
\end{tabular}

Çalışanların hasta güvenliği kültürü puanlarının eğitim düzeyine göre anlamlı farklılık göstermediği belirlenmiştir $(F=2,109 ; p>0,05)$.

Tablo 6: Hasta Güvenliği Kültürü Puanlarının Görev Yılı Değişkenine Göre Karşılaştırılması

\begin{tabular}{|c|c|c|c|c|c|c|c|}
\hline Boyut & Görev Yılı & $\mathbf{n}$ & $\overline{\mathbf{X}}$ & SS & $\mathbf{F}$ & $\mathbf{p}$ & \begin{tabular}{|c|} 
Anlamlı \\
Fark
\end{tabular} \\
\hline \multirow{5}{*}{$\begin{array}{l}\text { Hasta Güvenliği } \\
\text { Kültürü Toplam }\end{array}$} & A- 1 yıldan az & 32 & 3,51 & 0,43 & \multirow{5}{*}{5,204} & \multirow{5}{*}{0,0004} & \multirow{5}{*}{$\begin{array}{c}\mathbf{B}>\mathbf{A}, \mathbf{E} \\
\mathbf{C}>\mathbf{E} \\
\mathbf{D}>\mathbf{E}\end{array}$} \\
\hline & B- 1-5 y1l & 71 & 3,79 & 0,49 & & & \\
\hline & C- 6-10 y1l & 52 & 3,65 & 0,48 & & & \\
\hline & D- 11-15 y1l & 50 & 3,70 & 0,47 & & & \\
\hline & $\begin{array}{|llll|}\begin{array}{l}\text { E- } \\
\text { üzeri }\end{array} & \text { y1l } & \text { ve } \\
\end{array}$ & 76 & 3,48 & 0,35 & & & \\
\hline
\end{tabular}

Çalışanların hasta güvenliği kültürü puanlarının görev yılına göre anlamlı farklılık gösterdiği belirlenmiştir $(\mathrm{F}=5,204 ; \mathrm{p}<0,05)$. Farkın kaynağına ilişkin yapılan LSD post hoc testi sonuçlarına göre 1-5 yıl arasında görev 
y1lı bulunan çalışanların hasta güvenliği kültürü puanları, 1 yıldan az ve 16 yıl ve üzeri görev yılı bulunan çalışanların puanlarından anlamlı düzeyde daha yüksektir. 6-10 y1l arasında ve 11-15 y1l arasında görev y1lı bulunan çalışanların puanlarının ise 16 yıl ve üzeri görev yılı bulunan çalışanların puanlarından anlamlı düzeyde daha yüksek olduğu saptanmıştır. Bu bulgulara göre mesleğinde 1-5 y1l arasında tecrübesi olan çalışanlar diğer görev yılı süresine sahip çalışanlardan daha fazla hasta güvenliği kültürüne sahiptirler. Ayrıca görev yılı 16 yıl ve üzeri olan çalışanların hasta güvenliği kültürü düzeyinin diğer gruplara göre en düşük seviyede olduğu görülmektedir.

Tablo 7: Hasta Güvenliği Kültürü Puanlarının Görev Değişkenine Göre Karşılaştırılması

\begin{tabular}{|c|c|c|c|c|c|c|c|}
\hline Boyut & Görev & $\mathbf{n}$ & $\overline{\mathbf{X}}$ & SS & $\mathbf{F}$ & $\mathbf{p}$ & \begin{tabular}{|c|} 
Anlamlı \\
Fark \\
\end{tabular} \\
\hline \multirow{4}{*}{$\begin{array}{l}\text { Hasta Güvenliği } \\
\text { Kültürü Toplam }\end{array}$} & A- Doktor & 33 & 3,97 & 0,43 & \multirow{4}{*}{11,831} & \multirow{4}{*}{0,0002} & \multirow{4}{*}{$\begin{array}{c}\mathbf{A}>\mathbf{B}, \mathbf{C}, \\
\mathbf{D} \\
\mathbf{B}>\mathbf{C} \\
\mathbf{D}>\mathbf{C}\end{array}$} \\
\hline & B- Hemşire & 146 & 3,61 & 0,47 & & & \\
\hline & \begin{tabular}{|l|} 
C- \\
Teknisyen \\
/Tekniker*
\end{tabular} & 64 & 3,44 & 0,38 & & & \\
\hline & $\begin{array}{l}\text { D- Tibbi } \\
\text { Sekreter }\end{array}$ & 38 & 3,74 & 0,37 & & & \\
\hline
\end{tabular}

* Röntgen, Anestezi, Acil Tıp ve Laboratuvar Teknisyen/Teknikerleri

Çalışanların hasta güvenliği kültürü puanlarının göreve göre anlamlı farklılık gösterdiği belirlenmiştir $(\mathrm{F}=11,831 ; \mathrm{p}<0,05)$. Farkın kaynağına ilişkin yapılan LSD post hoc testi sonuçlarına göre doktorların hasta güvenliği kültürü puanları, hemşirelerin, teknisyen/teknikerlerin ve tıbbi sekreterlerin puanlarından anlamlı düzeyde daha yüksektir. Hemşirelerin ve tıbbi sekreterlerin hasta güvenliği kültürü puanlarının ise teknisyen/teknikerlerin puanlarından anlamlı düzeyde daha yüksek olduğu belirlenmiştir.

Tablo 8: Hasta Güvenliği Kültürü Puanlarının Görev Yeri Değişkenine Göre Karşılaştırılması

\begin{tabular}{|c|c|c|c|c|c|c|c|}
\hline Boyut & Görev Yeri & $\mathbf{n}$ & $\overline{\mathbf{X}}$ & SS & $\mathbf{F}$ & $\mathbf{p}$ & $\begin{array}{c}\text { Anlamlı } \\
\text { Fark }\end{array}$ \\
\hline \multirow{5}{*}{$\begin{array}{l}\text { Hasta Güvenliğ } \\
\text { Kültürü Toplam }\end{array}$} & A- Klinik & 117 & 3,53 & 0,40 & \multirow{5}{*}{8,689} & \multirow{5}{*}{0,0001} & \multirow{5}{*}{$\begin{array}{c}\text { B>A, E } \\
\mathrm{C}>\mathrm{A}, \mathrm{D}, \mathrm{E}\end{array}$} \\
\hline & B- Yoğun Bakım & 31 & 3,81 & 0,48 & & & \\
\hline & C-Ameliyathane & 35 & 3,95 & 0,46 & & & \\
\hline & D- Acil & 27 & 3,70 & 0,48 & & & \\
\hline & E- Diğer & 71 & 3,53 & 0,44 & & & \\
\hline
\end{tabular}


Çalışanların hasta güvenliği kültürü puanlarının görev yerine göre anlamlı farkl11ık gösterdiği belirlenmiştir $(\mathrm{F}=8,689 ; \mathrm{p}<0,05)$. Farkın kaynağına ilişkin yapılan LSD post hoc testi sonuçlarına göre yoğun bakım çalışanlarının hasta güvenliği kültürü puanları, klinik ve diğer alanlarda çalışanların hasta güvenliği kültürü puanlarından anlamlı düzeyde daha yüksektir. Ameliyathane çalışanlarının puanlarının ise klinik, acil ve diğer alanların puanlarından anlamlı şekilde daha yüksek olduğu saptanmıştır.

\section{Sonuç}

Araştırma bulgularına göre Konya Numune Hastanesi sağlık çalışanlarının hasta güvenliği kültürü toplam puan aritmetik ortalamaları 3,63 olarak orta düzeyin üzerinde bulunmuştur. Ölçek alt boyut puanlarında çalışanların en düşük algılarının personel sağlama $(2,82)$, hataya karşı cezalandırıcı olmayan yanıt $(3,10)$ ve hataların raporlanma sıklığında $(3,47)$; en yüksek algılarının ise üniteler içinde ekip çalışmasında $(4,19)$ olduğu belirlenmiştir. Bu istatistikler çalışanların birimlerinde yetersiz sayıda personel olduğunu düşündükleri $(2,82)$ ve bu eksikliği birimlerindeki ekip çalışmasını arttırarak $(4,19)$ çözmeye çalıştıkları şeklinde yorumlanabilir. Hataya karşı cezalandırıcı olmayan yanıt alt boyutunun ifade verileri $(3,10)$ incelendiğinde çalışanların yapılan hatalar karşısında suçlanacakları, şikayet edilecekleri ve yaptıkları hataların kişisel dosyalarında muhafaza edilecekleri endişesinde oldukları tespit edilmiştir.

Katılımcıların \%79,7'sinin $(n=224)$ Güvenlik Raporlama Sistemine (GRS) hiç bildirim yapmadığı belirlenmiştir. GRS bildirim oranlarının benzerlik gösterdiği çalışmalara sıkça rastlanmaktadır (Hisar vd., 2015: 154; Özdemir, 2014: 66; Tunçel, 2013: 42; Turasan, 2010: 57; Filiz, 2009: 56; Çakır, 2007: 155). Yapılan bildirim sayısının düşük olması, çalışanların hatalara karşı suçlayıcı ve cezalandırıcı bir yaklaşım gösterildiği şeklinde bir algıya sahip olmasından kaynaklandığı söylenebilir. Ayrıca birimlerini hasta güvenliği açısından başarısız ya da zayıf gören çalışan sayısının oldukça az olmasının bildirimin düşük oranda yapılmasına sebep olduğu düşünülebilir.

Elde edilen sonuçlara göre hasta güvenliği kültürü ile cinsiyet, medeni durum ve eğitim düzeyi arasında anlamlı farklılık bulunmamaktadır. Çalışanların hasta güvenliği kültürü puanlarının yaşa göre anlamlı farklılık gösterdiği; 18-25 yaş aralığında olan çalışanların hasta güvenliği kültürü puanlarının 26-35, 36-45 ile 46 ve üzeri yaş grubundaki çalışanların puanlarından anlamlı düzeyde daha yüksek olduğu söylenebilir. Ayrıca katılımcıların hasta güvenliği kültürü puanlarının 
görev y1lına göre anlamlı farklılık gösterdiği belirlenmiş, 16 yıl ve üzeri görev süresi olan çalışanların daha düşük hasta güvenliği kültürü algısına sahip olduğu görülmüsstür. Doktorların hasta güvenliği kültürü puanları, hemşirelerin, teknisyen/teknikerlerin ve tıbbi sekreterlerin puanlarından anlamlı düzeyde daha yüksek bulunmuş; hemşirelerin ve tıbbi sekreterlerin hasta güvenliği kültürü puanlarının ise teknisyen/teknikerlerin puanlarından anlamlı düzeyde daha yüksek olduğu belirlenmiştir. Yoğun bakım çalışanlarının hasta güvenliği kültürü puanları, klinik ve diğer alanlarda çalışanların hasta güvenliği kültürü puanlarından, ameliyathane çalışanlarının puanlarının ise klinik, acil ve diğer alanların puanlarından anlamlı şekilde daha yüksek olduğu saptanmıştır. Bu veriler doğrultusunda kurumlarda özellikle 26 yaş ve üzerindeki çalışanlara, 16 y1l ve üzerinde görev süresi olanlara, teknisyen/tekniker kadrosunda bulunanlara, yoğun bakım ya da ameliyathane haricindeki birimlerde çalışanlara hasta güvenliği eğitimleri verilmesinin, farkındalıklarının arttırılmasının ve güvenlik raporlama ile ilgili çalışmaların yapılmasının hasta güvenliği algı düzeyini yükselteceği söylenebilir.

İlgili literatürde bu çalışma sonuçlarıyla paralel olarak hasta güvenliği kültürü ile görev (Hisar vd., 2015: 153; Dağdelen, 2014: 76) ve görev yılı (Özdemir ve Şahin, 2015: 141) arasında anlamlı ilişki tespit edilen, cinsiyet (Durmaz, 2016: 31; Ebik, 2017: 45), medeni durum (Aydın, 2010: 47; Özdemir ve Şahin, 2015: 141) ve eğitim düzeyi (Tuncel, 2017: 54) arasında anlamlı ilişki tespit edilmeyen çalışmalara rastlanmaktadır. Bazı çalışmalarda ise bu çalışmada elde edilen bulguların aksine hasta güvenliği kültürü ile yaş (Ebik, 2017: 45) ve görev yeri (Özdemir, 2014: 79) arasında anlamlı ilişki olmadığı saptanmıştır.

Sağlık kurumlarında hasta güvenliği kültürünün oluşturulması için hatayı yapan bireye odaklanmadan yapılan hataların ortaya koyulmasının temel amaç olduğu, bunun için hatayı yapan bireylerle ilgili bilgilerin elde edilmesinin çeşitli yöntemlerle önlendiği ve kimliksizleştirmenin (anonimizasyon) öneminin tüm çalışanlar tarafından algılanması konusunda yöneticilerin etkin rol alması önerilebilir. Liderlerin destekleyici davranışlarının ve hasta güvenliği konusunda işgörenlerin ekip çalışmalarının geliştirilmesi, birimlerde personel eksikliklerinin giderilmesi ve çalışanlar arasında iletişimin arttırılması konusunda yapılacak çalışmaların hasta güvenliği kültürüne katkı sağlayacağı söylenebilir. 


\section{Kaynaklar}

Akalın, HE. (2004). Hasta Güvenliği Kültürü: Nasıl Geliştirebiliriz?, Ankem Dergisi, 18(2), s.12-13.

Altındiş, M. (2014). Hasta Güvenliği ve Komplikasyonlar, Sağllk Düşüncesi ve Tıp Kültürü Dergisi, 32, s.68-73.

Aydın, Ş. (2010). Bir Üniversite Hastanesinde Görev Yapan Hekim ve Hemşirelerin Hasta Güvenliği Kültürüne İlişkin Algılamalarl, Yüksek Lisans Tezi, Cumhuriyet Üniversitesi, Sağlık Bilimleri Enstitüsü, Hemşirelikte Yönetim Anabilim Dalı, Sivas.

Büyüköztürk, Ş. (2011). Sosyal Bilimler İçin Veri Analizi El Kitabı, 14. Bask1, Ankara: Pegem Akademi.

Clarke, J.B. (1993). Ethical İssues in Health Education, British Journal of Nursing, 2(10), s.533-538.

Çakır, A. (2007). Hasta Güvenliği Kültürü ile Kalite Yönetimi Sistemi Arasındaki İlişkinin Analiz, Yüksek Lisans Tezi, Dokuz Eylül Üniversitesi, Sosyal Bilimler Enstitüsü, Toplam Kalite Yönetimi Anabilim Dalı, İzmir.

Çakmakçı, M, Akalın, E. (2010). Hasta Güvenliği: Türkiye ve Dünya, Füsun Sayek TTB Raporları/Kitapları.

Çakmakçı, M. (2014). Hasta Güvenliğii: Bir Paradigma Değişimi, Sağllk Düşüncesi ve Tip Kültürü Dergisi, 33, s.6-11.

Dağdelen, Ü.A. (2014). Öğrenen Organizasyonlarda Hasta Güvenliği Kültürünün Değerlendirilmesi, Yüksek Lisans Tezi, Süleyman Demirel Üniversitesi, Sosyal Bilimler Enstitüsü, Sağlık Yönetimi Anabilim Dalı, Isparta.

Demirel, Ö. (2012). Öğretim Illke ve Yöntemleri: Öğretme Sanatı, Ankara: Pegem Akademi.

Durmaz, G. (2016). Cerrahi Hemşirelerinde Hasta Güvenliği Kültürü Algısını Etkileyen Faktörlerin Belirlenmesi, Yüksek Lisans Tezi, Yeditepe Üniversitesi, Sağlık Bilimleri Enstitüsü, Hemşirelik Anabilim Dalı, İstanbul.

Ebik, G.E. (2017). Hemşirelerde Örgütsel Sessizlik Düzeyinin Hasta Güvenliği Kültürü Üzerine Etkisi, Yüksek Lisans Tezi, Okan Üniversitesi, Sağlık Bilimleri Enstitüsü, Hemşirelik Yönetimi Anabilim Dal1, İstanbul.

Erengül, B. (1997). Kültür Sihirbazları, İstanbul: Evrim Yayınevi. 
Eroğlu, E.K. (2011). Bir Eğitim ve Araştırma Hastanesinde İş Yükünün Hasta Güvenliği Üzerindeki Etkisinin Belirlenmesi, Yüksek Lisans Tezi, Atılım Üniversitesi, Sosyal Bilimler Enstitüsü, Sağlık Kurumları İşletmeciliği Anabilim Dalı, Ankara.

Filiz, E. (2009). Hastanede Hasta Güvenliği Kültürü Algllamasının ve Sağlık Çalışanları İle Toplumun Hasta Güvenliği Hakkındaki Tutumunun Belirlenmesi, Yüksek Lisans Tezi, Selçuk Üniversitesi, Sağlık Bilimleri Enstitüsü, Halk Sağlığı Anabilim Dalı, Konya.

Gülay, H. (2016). Akreditasyon Belgesine Sahip Özel Bir Üniversite Hastanesinde Sağlık Çalışanlarının Bakış Açısıyla Hasta Güvenliği Kültürünün Değerlendirilmesi, Yüksek Lisans Tezi, İstanbul Medipol Üniversitesi, Sağlık Bilimleri Enstitüsü, Sağlık Yönetimi Anabilim Dalı, İstanbul.

Güven, R. (2007). Dezenfeksiyon ve Sterilizasyon Uygulamalarında Hasta Güvenliği Kavramı. 5. Ulusal Sterilizasyon Dezenfeksiyon Kongresi, Antalya, 411-442.

Hayran, O. (2009). Hasta Odaklı Sağlık Hizmetleri Yönetimi, Hasta Güvenliği Dergisi, s.20-23.

Hisar, K.M., Arslan, C.B., K1sa, S., Hisar, F. (2015). Bir Devlet Hastanesinde Çalışan Personelin Hasta Güvenliğine İlişkin Alg1 ve Görüşleri, Gümüşhane University Journal of Health Sciences, 4(1), s.148-161.

http://www.who.int/dg/speeches/2018/patient-safety-summit/en/ (Erişim Tarihi: 20.04.2018).

http:/www.who.int/mediacentre/news/releases/en/ (Erişim Tarihi: 23.04.2018).

http://www.tdk.gov.tr/index.php?option=com_gts\&arama=gts\&guid=TD

K.GTS.5ae18ab31dcbd7.26186012 (Erişim Tarihi: 20.04.2018).

https://grs.saglik.gov.tr/BM/UGRS.aspx (Erişim Tarihi: 02.04.2018).

İslamoğlu, A. H. (2009). Sosyal Bilimlerde Araştırma Yöntemleri, İzmit: Beta Basim.

Johnstone, M.J., Kanitsaki, O. (2006). Culture, Language and Patient Safety: Making The Link, International Journal for Quality in Health Care, 18(5), s.383-388.

Kohn, L., Corrigan, J., Donaldson, M. (1999). To Err is Human: Building a Safer Health System, Washington DC: National Academy Press.

Milligan, F, Dennis, S. (2005). Building a Safety Culture, Nursing Standart, 20(11), s.48-52. 
NPSA (National Patient Safety Agency) (2004). Seven Steps to Patient Safety, London: NPSA.

Ovalı, F. (2010). Hasta Güvenliği Yaklaşımları, Performans ve Kalite Dergisi, 1(1), s.33-43.

Özdemir, F.K., Şahin, Z.A. (2015). Hemşirelerin Hasta Güvenliği Kültürü Algıları: Kars İli Örneği, ODU Journal of Medicine, 2, s.139-144.

Özdemir, H. (2014). Cerrahi Hemşirelerinde Hasta Güvenliği Kültürü Alglarının Belirlenmesi: Afyonkarahisar'da Bir Uygulama, Yüksek Lisans Tezi, Afyon Kocatepe Üniversitesi, Sağlık Bilimleri Enstitüsü, Cerrahi Hastalıkları Anabilim Dalı, Afyonkarahisar.

Özkalp, E., Kırel, Ç. (2001). Örgütsel Davranış, Anadolu Üniversitesi Eğitim Sağlık ve Bilimsel Araştırma Vakfı Yayınları.

Reason, J. (2000). "Human Error: Models and Management", British Medical Journal. 320. s.768-770.

Reason, J. (1995). Understanding Adverse Events: Human Factors, Quality in Health Care, 4, s.80-89.

Resmi Gazete. (2009). Sağlık Kurum ve Kuruluşlarında Hasta ve Çalışan Güvenliğinin Sağlanması ve Korunmasına İlişkin Usul ve Esaslar Hakkında Tebliğ, 29 Nisan 2009, Sayı: 27214.

Schoen, C., Osborn, R., Huynh, P.T., Doty, M., Zapert, K., Peugh, J., Davis, K. (2005). Taking The Pulse of Health Care Systems: Experiences of Patients with Wealth Problems in Six Countries. Health Affairs, 24, W5_509-W5_525.

Serbest, Ş. (2011). Hasta Güvenliği Iç̧in Hemşirelik Uygulamaları, 13. Ulusal Hemşirelik Kongresi Sunumu, 2011.

Sorra, J., Nieva, V.F. (2004). Hospital Survey On Patient Safety Culture, Agency for Healthcare Research and Quality.

Tuncel, H. (2017). Örgüt Kültürünün Ameliyathane Hemşirelerinde Hasta Güvenliği Üzerine Etkisi, Yüksek Lisans Tezi, Koç Üniversitesi, Sağlık Bilimleri Enstitüsü, Hemşirelik Programı, İstanbul.

Tunçel, K. (2013). Hemşirelerin Hasta Güvenliği Kültürünü Algllama Düzeyi ve Hasta Güvenliği Uygulamalar, Yüksek Lisans Tezi, Atatürk Üniversitesi, Sağlık Bilimleri Enstitüsü, Hemşirelikte Yönetim Anabilim Dal1, Erzurum.

Turasan, B.A. (2010). Bir Psikiyatri Hastanesinde Hasta Güvenliği Kültürü Düzeyi ve Güvenlik Raporlamanın Incelenmesi, Yüksek 
Lisans Tezi, Ege Üniversitesi, Sağlık Bilimleri Enstitüsü, Psikiyatri Hemşireliği Anabilim Dalı, İzmir.

Tütüncü, Ö., Küçükusta, D., Yağcı, K. (2007). Toplam Kalite Yönetimi Kapsamında Hasta Güvenliği Kültürü ve Bir Ölçme Arac1, Dokuz Eylül Üniversitesi Sosyal Bilimler Enstitüsü Dergisi, 9(1), s.519533.

Uzun, Ö. (2009). Hastanelerde Hasta Güvenliğini Olumsuz Etkileyen Etmenler, 5. Nöroşirürji Hemşireliği Kongresi.

Yetginlioğlu, Ö. (2009). Să̆lık Kurumlarında Hasta Güvenliğinin Sağlanmasında Kalite ve Akreditasyon Çalışmalarının Önemi: Ankara İlindeki İki Hastanede Hasta Güvenliği Çalışmalarının Değerlendirilmesine Yönelik Mukayeseli Bir Uygulama, Yüksek Lisans Tezi, Selçuk Üniversitesi, Sosyal Bilimler Enstitüsü, İşletme Anabilim Dalı, Konya. 
